CLINICAL STUDY

\title{
Long-term management in five cases of TSH-secreting pituitary adenomas: a single center study and review of the literature
}

\author{
Tina Kienitz, Marcus Quinkler, Christian J Strasburger and Manfred Ventz \\ Clinical Endocrinology, Department of Internal Medicine, Gastroenterology, Hepatology and Endocrinology, Charité Campus Mitte, Charité \\ Universitätsmedizin Berlin, Charitéplatz 1 D-10117, Berlin, Germany
}

(Correspondence should be addressed to M Quinkler; Email: marcus.quinkler@charite.de)

\begin{abstract}
Objective: TSH-secreting pituitary tumors (TSH-omas) are a rare cause of hyperthyroidism and account for $<1 \%$ of all pituitary adenomas. Failure to recognize the presence of a TSH-oma may result in dramatic consequences such as thyroid ablation that may cause further growth in pituitary tumor. The primary goal of the treatment of TSH-omas is to remove the pituitary tumor. Medical treatment includes dopaminergic agonists or somatostatin analogs.

Methods and results: We report five cases of TSH-oma diagnosed between 1997 and 2006 and review the literature. All the patients are females with an age range from 54 to 65 years at diagnosis. Four of the five patients had at least one event of thyroid surgery due to goiter or nodule of unknown dignity. Three of the five patients had a stroke before the diagnosis of TSH-oma, probably due to hypertension, or smoking and contraceptive treatment. One patient with invasive tumor growth received stereotactic radiotherapy (and developed panhypopituitarism after operation), another patient received somatostatin analogs preoperatively and successfully underwent transsphenoidal operation. Three of the five patients received dopaminergic agonists (bromocriptine $5 \mathrm{mg}$ daily or cabergoline 0.5$0.75 \mathrm{mg}$ per week), because they refused surgical therapy or the tumor was stable under dopaminergic therapy. All patients have been followed-up for 2.5-8 years. A normalization of circulating thyroid hormone levels was achieved in all patients. The patient who underwent operation shows no recurrence of the disease. The other patients have a stable pituitary mass without signs of growth. Conclusion: We report the successful long-term treatment of TSH-omas with different therapies.
\end{abstract}

European Journal of Endocrinology 157 39-46

\section{Introduction}

Thyrotropin (TSH)-secreting pituitary adenomas (TSH-omas) account for $<1 \%$ of all pituitary adenomas $(1,2)$ with an overall prevalence of about one in one million and cause secondary hyperthyroidism. Thus, they are a rare cause of thyrotoxicosis when compared with the more prevalent 'classical' primary hyperthyroidism. However, secondary hyperthyroidism has to be ruled out as differential diagnosis of elevated thyroid hormone levels. Failure to recognize a TSH-oma may lead to improper therapy attempts and dramatic consequences for the patient including complications such as visual field defects due to compression of the optic chiasm or hypopituitarism.

With the introduction and routine use of ultrasensitive immunometric TSH assays and improved imaging techniques, it was possible to diagnose TSH-omas more easily and at earlier stages. First-line therapy of patients with TSH-oma is transsphenoidal resection of the tumor by which about one-third of all patients can be cured completely (2). However, if surgery is contraindicated or declined, pituitary radiotherapy and/or administration of somatostatin analogs or dopaminergic agonists should be taken into consideration. In this paper, we present five cases of TSH-oma from our clinic. We will outline the individual characteristics of the cases, both their clinical and biochemical profiles that led to different treatment strategies and provide a review of the literature in this context. Although the number of patients in this series is limited and may therefore not be representative, this paper will provide new insight into the management of TSH-omas with a benign clinical course by means of medical therapy.

\section{Clinical cases}

Since 1997, we were able to diagnose five TSHproducing pituitary adenomas in our center. General data of these five cases are summarized in Table 1. All patients were female and on average 58.6 years old at the time of diagnosis (range: 54-65 years). Table 2 provides an overview of biochemical findings at the time of diagnosis of TSH-oma and at last follow-up visit. 
Table 1 Summary of five cases with thyrotropinoma (TSH-oma): general data.

\begin{tabular}{|c|c|c|c|c|c|c|c|}
\hline Case no. & Gender & $\begin{array}{c}\text { Age at } \\
\text { diagnosis }\end{array}$ & $\begin{array}{l}\text { Latency onset of } \\
\text { hyperthyroidism } \\
\text { - diagnosis of } \\
\text { TSH-oma }\end{array}$ & $\begin{array}{c}\text { Thyroid } \\
\text { surgery prior to } \\
\text { the diagnosis } \\
\text { of TSH-oma }\end{array}$ & Size & $\begin{array}{l}\text { Follow-up } \\
\text { (from the time of } \\
\text { diagnosis) }\end{array}$ & Therapy \\
\hline 1 & $\mathrm{~F}$ & 54 & 16 years & Yes & Macroadenoma & $>7.5$ years & $\begin{array}{l}\text { Somatostatin analogs and } \\
\text { pituitary radiotherapy }\end{array}$ \\
\hline 2 & $\mathrm{~F}$ & 57 & 10.5 years & Yes & Microadenoma & $>2.5$ years & Dopamine agonist \\
\hline 3 & $\mathrm{~F}$ & 65 & 16 years & Yes & Microadenoma & $>8$ years & Dopamine agonist \\
\hline 4 & $\mathrm{~F}$ & 60 & 19 years & Yes & Macroadenoma & $>8$ years & Dopamine agonists \\
\hline 5 & $\mathrm{~F}$ & 57 & 1 year & No & Macroadenoma & $>7.5$ years & $\begin{array}{l}\text { Transsphenoidal surgery, } \\
\text { (somatostatin analogs } \\
\text { and antithyroid medi- } \\
\text { cation preoperatively) }\end{array}$ \\
\hline
\end{tabular}

\section{Case 1}

In 1981, this 38-year-old woman presented with hyperthyroidism and elevated TSH levels for the first time. Nevertheless, the patient underwent subtotal thyroidectomy and two courses of radioiodine therapy. Thereafter, she developed symptoms of clinical hypothyroidism and needed thyroid hormone replacement. Probably due to arterial hypertension and hypercholesterinemia, our patient had two apoplectic insults in 1989 and 1992 with incomplete, right-sided hemiparesis and Broca's aphasia. However, how far the patient's hyperthyroidism contributed to the insults can only be speculated on. In addition, our patient developed epilepsy in 1989 , which has been treated with phenytoin.

In 1997, a macroadenoma (size $15 \times 20 \mathrm{~mm}$ ) of the pituitary gland was diagnosed by magnetic resonance imaging (MRI) scan. The optic chiasm was compressed and the sphenoid sinus was infiltrated. As a 54-year-old the woman was referred to our clinic. In spite of peripheral euthyroidism, TSH was markedly elevated (Table 2). Alpha subunits ( $\alpha$-SUs) were also clearly elevated despite the gonadotrope insufficiency of our patient. Due to the patient's poor general condition, surgical approach of the TSH-oma was contraindicated.
Dopamine agonist therapy was considered, but following administration of $0.25 \mathrm{mg}$ cabergoline, the patient developed tachycardia and a paradoxical elevation of TSH levels to $158 \mathrm{mU} / \mathrm{l}$ so cabergoline was stopped immediately. Somatostatin analogs only temporarily succeeded in suppressing TSH levels with the elevation of TSH in spite of increased dosages (octreotide up to $900 \mu \mathrm{g} /$ day). However, on MRI, shrinkage of the tumor without compression of the optic chiasm could be seen. Octreotide $300 \mu \mathrm{g} /$ day was stopped in July 1998 since the tumor volume could not be reduced any further. After a year, TSH began to rise again dramatically (up to $488 \mathrm{mU} / \mathrm{l}$ ) despite peripheral euthyroidism (free tri-iodothyronine $\left(\mathrm{fT}_{3}\right), 4.0 \mathrm{pmol} / \mathrm{l}$, normal 3.4-7.0 pmol/l; free thyroxine $\left(\mathrm{fT}_{4}\right) 10.9 \mathrm{pmol} /$ l, normal 11.0-25.0 pmol/l) under thyroid hormone supplementation. Moderate tumor growth was detected on MRI. In spring 2000, our patient finally underwent stereotactic radiotherapy of the pituitary $(51 \mathrm{~Gy})$ and developed panhypopituitarism later on. After 5 years of radiotherapy, the TSH-oma was under control with a small but stable tumor mass, persistently elevated TSH levels, and peripheral euthyroidism under thyroid hormone replacement therapy (Table 2). However, since the diagnosis of pancreatic carcinoma $\left(\mathrm{pT}_{3}, \mathrm{~N} 1\right.$,

Table 2 Laboratory findings in five cases of thyrotropinoma (TSH-oma) at the time of diagnosis and at last follow-up visit.

\begin{tabular}{|c|c|c|c|c|c|c|c|c|c|c|c|}
\hline \multirow[b]{2}{*}{$\begin{array}{l}\text { Case } \\
\text { no. }\end{array}$} & \multicolumn{7}{|c|}{ At the time of diagnosis } & \multicolumn{4}{|c|}{ At last follow-up visit } \\
\hline & $\begin{array}{l}\text { TSH } \\
(\mathrm{mU} / \mathrm{l})\end{array}$ & $\begin{array}{c}\mathrm{fT}_{3} \\
\text { (pmol/l) }\end{array}$ & $\begin{array}{c}\mathrm{fT}_{4} \\
(\mathrm{pmol} / \mathrm{l})\end{array}$ & $\begin{array}{c}\text { Alpha SU } \\
(\mathrm{U} / \mathrm{I})\end{array}$ & $\begin{array}{c}\text { Alpha } \\
\text { SU/TSH }\end{array}$ & $\begin{array}{l}\text { PRL } \\
\text { (ng/ml) }\end{array}$ & $\begin{array}{l}\text { SHBG } \\
(\mathrm{nmol} / \mathrm{l})\end{array}$ & $\begin{array}{l}\text { TSH } \\
(\mathrm{mU} / \mathrm{l})\end{array}$ & $\begin{array}{c}\mathrm{fT}_{3} \\
(\mathrm{pmol} / \mathrm{l})\end{array}$ & $\begin{array}{c}\mathrm{fT}_{4} \\
(\mathrm{pmol} / \mathrm{l})\end{array}$ & $\begin{array}{l}\text { PRL } \\
(\mathrm{ng} / \mathrm{ml})\end{array}$ \\
\hline 1 & $94.8-126.0^{a}$ & $5.4-5.5^{\mathrm{a}}$ & $18.9-25.0^{\mathrm{a}}$ & $4.58^{a}$ & $0.37^{a}$ & 8.2 & n.d. & $91.8^{\mathrm{a}}$ & $4.0^{\mathrm{a}}$ & $15.5^{\mathrm{a}}$ & 11.1 \\
\hline 2 & $5.0-8.2^{\mathrm{a}}$ & $5.9-7.8^{\mathrm{a}}$ & $15.7-32.9^{\mathrm{a}}$ & $5.1^{\mathrm{a}}$ & $9.11^{\mathrm{a}}$ & 12.8 & $59.0-178.0^{a}$ & $6.1^{\mathrm{b}}$ & $5.9^{b}$ & $14.3^{\mathrm{b}}$ & $0.8^{\mathrm{b}}$ \\
\hline 3 & $2.7-3.8^{\mathrm{a}}$ & $8.1-8.3^{\mathrm{a}}$ & $34.2-49.5^{\mathrm{a}}$ & $1.49^{\mathrm{a}}$ & $5.51^{\mathrm{a}}$ & 8.8 & $45.1^{\mathrm{a}}$ & $1.8^{\mathrm{b}}$ & $5.1^{b}$ & $17.8^{\mathrm{b}}$ & $<0.3^{\mathrm{b}}$ \\
\hline 4 & $2.0-3.2^{\mathrm{a}}$ & $7.5-8.9^{\mathrm{a}}$ & $23.6-26.0^{\mathrm{a}}$ & $0.95^{\mathrm{a}}$ & $2.97^{\mathrm{a}}$ & 9.6 & n.d. & $2.5^{\mathrm{b}}$ & $5.5^{\mathrm{b}}$ & $19.9^{\mathrm{b}}$ & $<0.3^{\mathrm{b}}$ \\
\hline 5 & $6.9-8.6$ & $8.3-9.4$ & $34.5-42.8$ & n.d. & n.d. & 32.4 & n.d. & $1.4^{\mathrm{c}}$ & $4.9^{c}$ & $12.0^{c}$ & 3.9 \\
\hline
\end{tabular}

TSH (normal 0.6-4.6 mU/l), $\mathrm{fT}_{3}$ (normal 3.4-7.2 pmol/l), $\mathrm{fT}_{4}$ (normal 11.0-23.0 pmol/l), alpha SU ( $\alpha$-SU, normal premenopausal 0.1-0.5 U/l, postmenopausal 0.6-1.5 U/I), $\alpha$-SU/TSH (according to Beck-Peccoz et al. (2) reference values for normogonadotropic controls with normal TSH <5.7, with high TSH <0.7, for hypergonadotropic controls with normal TSH $<29.1$, with high TSH $<1.0)$, prolactin (PRL, normal $2.0-23.0 \mathrm{ng} / \mathrm{ml}$ ), sex hormone-binding globulin (SHBG, normal female $18-83 \mathrm{nmol} / \mathrm{l})$, n.d. (not done).

aDuring thyroid hormone replacement therapy.

bDuring dopamine agonist therapy.

${ }^{\mathrm{C}}$ During iodine supplementation. 
Mx, R2, G2) in 2004, she declined any further therapy. Multiple endocrine neoplasia type 1 was considered, but family history for endocrine neoplasia was negative and our patient showed no clinical symptoms or biochemical results indicative of hyperparathyroidism. Since April 2005, the patient has been lost to follow-up.

\section{Case 2}

In 1993, a 47-year-old woman presented with goiter and hyperthyroidism. Total peripheral thyroid hormones were elevated, but TSH remained in the normal range. However, TSH could be stimulated only poorly in the TRH test from 1.9 to $3.0 \mathrm{mU} / \mathrm{l}$ (normal baseline range: $0.3-4.0 \mathrm{mU} / \mathrm{l}$ ). Thyroid suppression scintigraphy with technetium-99m was inadequate and interpreted as disseminated autonomy of the thyroid gland. In April 1994, the patient underwent subtotal thyroidectomy.

In the following years, the patient developed mild hyperthyroidism without clinical symptoms, but TSH increased up to $8.2 \mathrm{mU} / \mathrm{l}$, with an $\alpha$-SU of $5.1 \mathrm{U} / \mathrm{l}$ (normal range premenopausal: $<0.5 \mathrm{U} / \mathrm{l}$ ) under thyroid hormone supplementation. An MRI scan showed a microadenoma of the pituitary gland (size $4 \mathrm{~mm}$ ). The patient was referred to our outpatient clinic, and in 2005, thyroid hormone supplementation was stopped completely. Despite hyperthyroidism, the patient declined surgery of the TSH-oma. Therapy with cabergoline $(0.5 \mathrm{mg} /$ week) was started under which peripheral thyroid hormone levels decreased to normal ranges. After 18 months of initial dopamine agonist therapy, our patient remains euthyroid with a stable pituitary microadenoma.

\section{Case 3}

This female patient had undergone resection of a large goiter at the age of 18 years. After 28 years, she was operated again due to nodular goiter and developed latent hypoparathyroidism postoperatively. At the age of 65, she presented at our clinic with hyperthyroidism: peripheral thyroid hormones were mildly elevated and TSH levels were persistently in the upper normal range (Table 2). TRH test showed only poor stimulation of TSH from 2.9 to $5.3 \mathrm{U} / \mathrm{l}$. In addition, suppression scintigraphy with $\mathrm{T}_{3} 75 \mu \mathrm{g} /$ day over 10 days failed to sufficiently suppress the thyroid gland. The $\alpha$-SU was in the upper normal range $(1.49 \mathrm{U} / \mathrm{l}$; normal range postmenopausal $0.6-1.5 \mathrm{U} / \mathrm{l})$. MRI scan showed a microadenoma of the pituitary (size $7 \mathrm{~mm}$ ) with a slight deviation of the pituitary stalk. However, pituitary surgery was declined by the patient. Due to increasing levels of peripheral thyroid hormones, 2 years after initial presentation, we started medical therapy with bromocriptine $5 \mathrm{mg} /$ day and propanolol $25 \mathrm{mg}$ /day. After 4 years, the patient is euthyroid with decreased TSH levels, while the pituitary tumor is stable in size.

\section{Case 4}

In 1979, this 41-year-old woman was diagnosed with a euthyroid goiter with an autonomous nodule. However, suppression scintigraphy failed to suppress the thyroid tissue at this time. After an apoplectic insult in 1980, probably due to smoking and contraceptive medication, the patient was referred to our clinic. TSH could not be stimulated sufficiently in a TRH test (from 6.9 to $7.0 \mathrm{mU} / \mathrm{l}$ ), while peripheral thyroid hormone levels were elevated (total $\mathrm{T}_{3} 3.6 \mathrm{nmol} / \mathrm{l}$ ). In April 1981, thyroid scintigraphy showed a cold nodule for which the patient was operated, but histology ruled out malignancy of the tissue. The patient's hyperthyroidism was symptomatically treated with beta blockers. Peripheral thyroid hormone levels remained moderately elevated under thyroid hormone supplementation, while TSH was in the upper normal range, but temporarily suppressible by increasing dosages of thyroid hormone (triiodthyronine $50 \mu \mathrm{g} /$ day: TSH $3.2 \mathrm{mU} / \mathrm{l}$; triiodthyronine $75 \mu \mathrm{g}$ /day: TSH $1.4 \mathrm{mU} / \mathrm{l})$.

In 1998, molecular genetic investigations (analysis of exons 9 and 10 of thyroid hormone receptor $\beta$ ) were done on this patient, but a mutation for resistance to thyroid hormone (RTH) could not be detected. $\alpha$-SUs were not elevated (0.95-1.10 U/l) in our patient. However, 3,5,3'-triiodothyroacetic acid (1.05 mg/day), did not sufficiently suppress TSH, which is reported to occur in patients with pituitary RTH (3).

Finally, MRI scan revealed a macroadenoma of the pituitary gland (size $13 \times 7 \mathrm{~mm}$ ) with deviation of the pituitary stalk. This finding was regarded as reactive hyperplasia of the pituitary, due to the patient's poor compliance regarding her medication. An MRI scan taken after 1 year showed unchanged size of the pituitary mass despite stricter thyroid hormone therapy and better compliance. Yet possible occurrence of RTH in combination with non-functioning pituitary adenoma could not be excluded at this time point.

Pituitary adenomectomy was declined by the patient; dopamine agonist therapy with bromocriptine $2.5 \mathrm{mg} /$ day was started in 2001, and changed to cabergoline $0.75 \mathrm{mg} /$ week in 2004. Since then, our patient has been euthyroid with normal TSH levels and a stable tumor size on MRI (Table 2). Taking into consideration all clinical data and biochemical tests in combination with the efficacy of dopamine agonists in stabilizing thyroid function (TSH before administration of bromocriptine $3.7 \mathrm{mU} / \mathrm{l}, 4$ months after start of therapy $1.7 \mathrm{mU} / \mathrm{l}$ ), diagnosis of TSH-oma may be the most reasonable diagnosis.

\section{Case 5}

In 1997, this 56-year-old woman with hypertension had an insult resulting in left-sided hemiparesis. At this time, hyperthyroidism was diagnosed with moderate symptoms of thyrotoxicosis such as tachycardia, 
intolerance to heat and restlessness, elevated peripheral thyroid hormones, and TSH levels in the upper range of normal. The patient received methimazole $5 \mathrm{mg} /$ day. After 1 year, TSH levels had increased to $9 \mathrm{mU} / \mathrm{l}$ while the patient remained hyperthyroid. Skull X-ray imaging showed a sellar dilatation. The patient was referred to our clinic for further diagnostic tests.

On MRI scan, a macroadenoma of the pituitary (size $10 \mathrm{~mm}$ ) with deviation of the pituitary stalk was diagnosed. To achieve euthyroidism before surgical resection of the TSH-oma, a therapy with thiamazole was started. However, increasing dosages were not able to lower thyroid hormone levels significantly. Somatostatin receptor scintigraphy was positive and allowed additional administration of a somatostatin analog (octreotide $300 \mu \mathrm{g} /$ day). As soon as euthyroidism was reached, our patient underwent transsphenoidal surgery. Postoperatively she developed hypothyroidism and diabetes insipidus, and consequently received iodine supplementation and desmopressin. Immunohistochemistry of the tumor showed positive staining for TSH and MIB1 of $<1 \%$. Increased prolactin levels preoperatively $(32.4 \mathrm{ng} / \mathrm{ml}$, normal $2.0-23.0 \mathrm{ng} / \mathrm{ml}$ ) without symptoms of hyperprolactinemia were probably due to the compression of the pituitary gland or hypothalamus-pituitary disconnection. Three weeks after the operation, euthyroidism was reached and has been stable for 8 years without recurrence of the adenoma.

\section{Discussion}

Both TSH-secreting pituitary adenomas and the syndrome of RTH are syndromes of "inappropriate secretion of TSH' (IST) (4). It is essential to differentiate between them, especially as in both syndromes patients present with high peripheral thyroid hormone levels, inappropriately normal or elevated levels of TSH and symptoms of thyrotoxicosis. The hormonal profile of TSH-omas is classically characterized by an escape of TSH from the feedback loop. Due to their autonomy, they are also called neoplastic IST $(2,4)$. In contrast, RTH is nonneoplastic (2, 4-8). In the pituitary form of RTH, mutations in the gene coding for thyroid hormone receptor $\beta$ prevent a detection of peripheral thyroid hormones by the pituitary, which results in increased levels of TSH and hyperthyroidism. While it is mainly the pituitary gland being insensitive to thyroid hormones, other tissues do not show a resistance to thyroid hormones in this form of the syndrome (9). A mutation in the gene coding for thyroid hormone receptor $\beta$ confirms diagnosis of RTH. Nevertheless, in about $10 \%$ of cases, no mutations can be found $(5,9)$.

In contrast, pituitary hyperplasia comes with low levels of thyroid hormones (2). Longstanding peripheral hypothyroidism causes thyrotropic cells to grow and produce high levels of TSH (lack of negative feedback). Indeed, the syndrome can be treated easily by thyroid hormone replacement therapy, which is followed by subsequent shrinkage of the pituitary mass (Fig. 1).

Most patients of our series underwent an unfortunate and complicated diagnostic process before being seen at our clinic. Four of our five patients had thyroid surgery before being referred to our center, three of them due to goiter and one because of a thyroid nodule. In addition, one of the four patients underwent radioiodine therapy and was treated with antithyroid drugs (case 1). Latency between the onset of hyperthyroidism and diagnosis of TSH-oma was 12.5 years (range: 1-19 years). Indeed, this underlines the diagnostic challenge of TSH-omas. It has to be taken into consideration that in at least three cases, thyroid surgeries took place before 1983 when TSH assays were not as sensitive as nowadays and TSH measurements were not yet performed as first-line thyroid function tests. However, we cannot exclude that similar mechanisms which lead to aggressive transformation of pituitary cells after adrenalectomy in Nelson's syndrome also occur in patients with previous thyroid ablation (10) as can be seen in our first case. In accordance with this hypothesis, patients with previous thyroid surgery more often present with invasive macroadenomas (2). That is why misdiagnosis of TSH-oma and inappropriate thyroid ablation need to be avoided as they may have dramatic consequences.

Figure 2 may serve as an algorithm in diagnosis and treatment of TSH-oma. Although all of our patients were females, a gender difference in the prevalence of TSH-oma is not known (2). Signs of thyrotoxicosis may vary from severe to absent. However, more than $90 \%$ of all patients with TSH-oma present with goiter. Compression syndrome including headaches and visual-field defects due to tumor invasion or suprasellar extension may be dominating over symptoms of thyrotoxicosis (2). Nevertheless, since imaging techniques and thyroid testing have greatly improved during the last decades, pituitary tumors may now be diagnosed at earlier stages. In about $30 \%$ of TSH-omas, neoplastic TSH secretion is accompanied by dysregulation of other endocrine axes of the pituitary (mixed TSH-omas) (2) resulting in additional symptoms of hormone hypersecretion such as galactorrhea, menstrual disorders, loss of libido, or acromegalic features. None of our patients showed symptoms or biochemical signs indicative of mixed TSH-oma. In case 5, the patient presented with mild hyperprolactinemia, most likely due to compression of the pituitary gland or hypothalamuspituitary disconnection.

In particular, the presence of neurological compression symptoms and concomitant hypersecretion of other pituitary hormones is indicative of TSH-oma, differentiating it from pituitary RTH. On the other hand, pituitary RTH comes with a positive family history in more than $80 \%$ of the cases (2); familial cases in TSHoma have not been documented. 


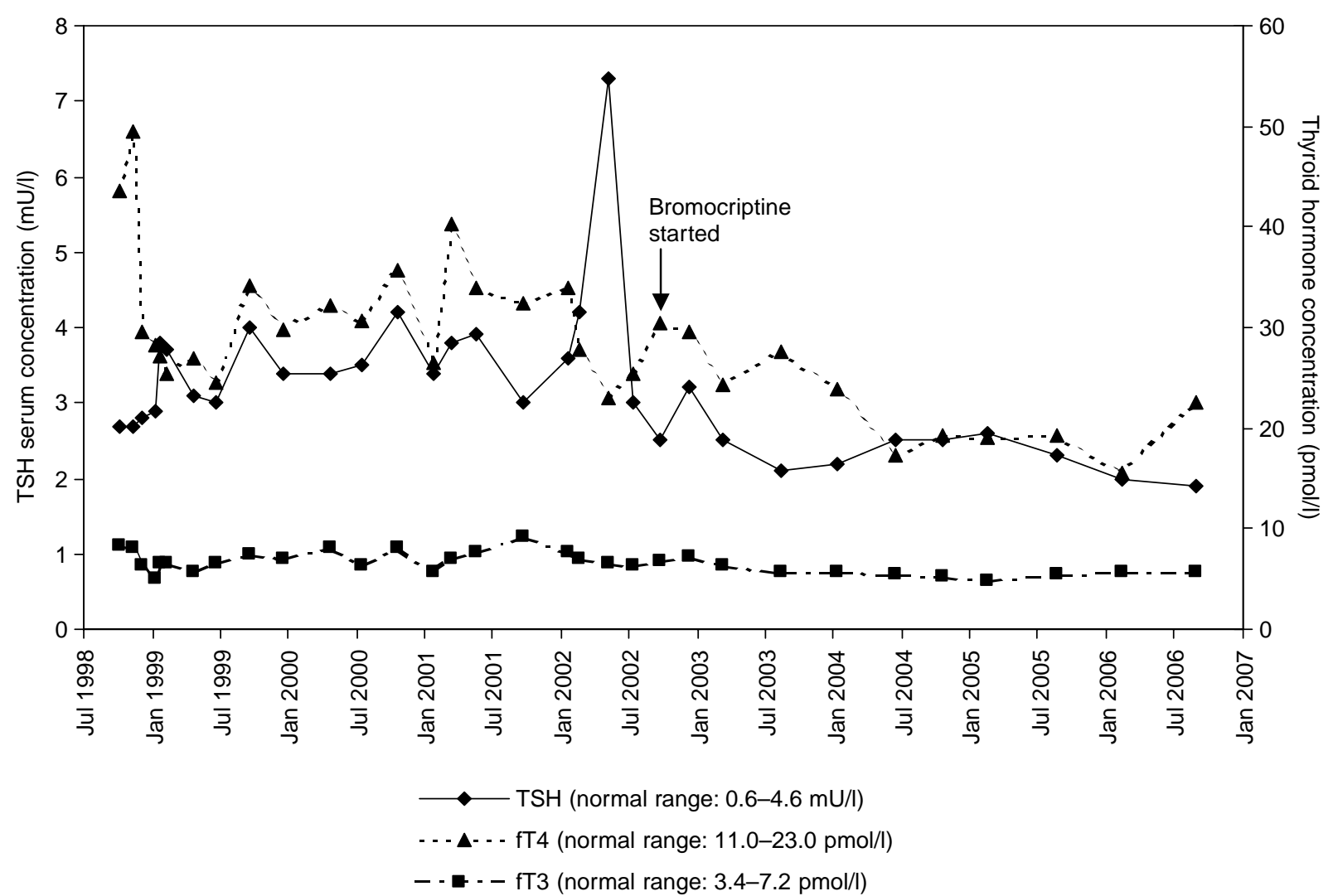

Figure 1 Biochemical data of patient 3 (condition after subtotal thyroidectomy in 1951 and 1979). $f T_{3}$, free $T_{3} ; \mathrm{fT}_{4}$, free $T_{4}$.

Two of our patients showed at least mild clinical signs of thyrotoxicosis at the time of diagnosis. However, none of them suffered from headaches at this time. One patient had visual field defects that were most likely related to apoplectic insults in her history. It is striking that apoplectic insults occurred in the medical history of three cases. However, we do not see a clear correlation of these incidents with the patients' hyperthyroidism, because two of them had severe hypertension and one was on contraceptive medication and was smoking. In addition, two patients had a positive family history for cerebral ischemia and cardiovascular diseases.

Baseline TSH levels are not reliable diagnostic markers for TSH-oma since neoplasm-derived TSH shows a higher bioactivity (11). This may explain conditions in which free $\mathrm{T}_{3}$ and $\mathrm{T}_{4}$ are elevated, while TSH levels remain normal. Other markers of thyroid hormone action may be increased as well, such as sex hormone-binding globulin (SHBG), cholesterol, angiotensin converting enzyme or carboxyterminal cross-linked telopeptide of type $1 \mathrm{col}-$ lagen (2). SHBG is known to be elevated in $80 \%$ of patients with TSH-oma, in contrast with normal SHBG levels in patients with RTH. After all, inadequate measurement of TSH and peripheral thyroid hormones must always be considered. This situation may occur, for example, in association with increased levels of hormone-binding globulins (thyroxine-binding globulin, albumin, transthyretin), familial dysalbuminemic hyperthyroxinemia, presence of anti- $\mathrm{T}_{4}$ autoantibodies, or medical therapy with amiodarone $(2,9)$. In these cases, laboratory measurements may have to be repeated with appropriate methods.

Indeed, no biochemical marker or dynamic test is solely pathognomonic in the diagnosis of TSH-oma. Brucker-Davis et al. suggested that a combination of TRH stimulation test, $\alpha$-SU, and $\alpha$-SU/TSH ratio is indicative of TSH-oma (12). While they recommended TRH test and $\alpha$-SU in patients with intact thyroid, in those with previous thyroid treatment $\alpha$-SU and $\alpha$-SU/ TSH ratio had the best diagnostic value. In our patients, the combination of TRH test and $\alpha$-SU/TSH ratio was strongly suggestive of TSH-oma. According to BruckerDavis, the TRH test is indeed less sensitive in patients with prior thyroid ablation, but remains a highly specific diagnostic tool (12). On the other hand, $\mathrm{T}_{3}$ suppression test may help to differentiate TSH-omas from secondary pituitary hyperplasia. It is however contraindicated in patients with a history of epilepsy, apoplectic insults, or coronary heart disease.

TSH, FSH, and LH share a common $\alpha$-SU that is cosecreted with the pituitary hormones and therefore may be diagnostic in TSH-omas. Baseline $\alpha$-SUs were measured in four of our patients. Taking their gonadal status into consideration, $\alpha$-SUs were normal in one, borderline in another, and clearly elevated in two cases. The molar $\alpha$-SU/TSH ratio is calculated using the 


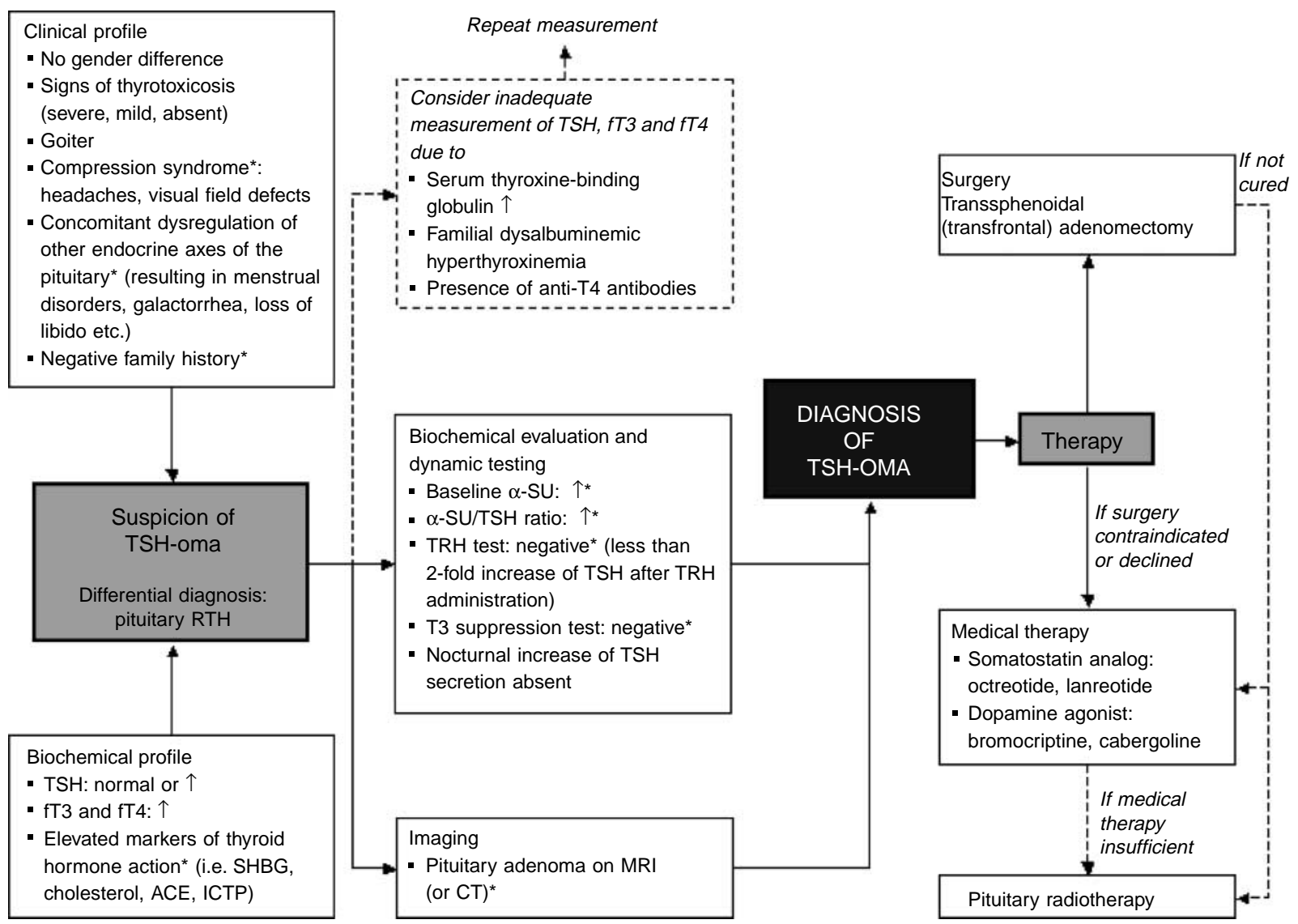

Figure 2 Overview of diagnosis and therapy of TSH-oma. $\mathrm{fT}_{3}$, free $\mathrm{T}_{3} ; \mathrm{fT}_{4}$, free $\mathrm{T}_{4}$; $\mathrm{SHBG}$, sex hormone-binding globulin; ACE, angiotensinconverting enzyme; ICTP, carboxyterminal cross-linked telopeptide of type 1 collagen; $\alpha$-SU, alpha subunit; *Parameters indicative of TSH-oma as compared with patients with pituitary RTH.

formula $(\alpha-\mathrm{SU}$ in $\mu \mathrm{g} / \mathrm{l}$ divided by $\mathrm{TSH}$ in $\mathrm{mU} / \mathrm{l}) \times 10$ (13). $\alpha$-SU/TSH ratios are considered to be more specific and were clearly indicative of TSH-oma in three of our patients. In case 1 , the ratio was not elevated, but considering the patient's gonadotropic insufficiency, it was still of diagnostic value. However, analyzing TSHomas reported in the literature, TSH secretion was often accompanied by an unbalanced secretion of its $\alpha$-SU (2). TSH-omas may occur as mixed $\mathrm{TSH} / \alpha-\mathrm{SU}$ adenomas (14), which are composed of two different cell types that mostly secret $\alpha$-SU alone and in about $5 \% \alpha$-SU and TSH simultaneously. This might explain variant responses of $\alpha$-SU and TSH in TRH tests and occurrence of extremely high $\alpha$-SU/TSH ratios in certain patients. Finally, diagnosis of autonomic TSH secretion may be supported by the finding of loss of nocturnal increase in TSH (15).

As with biochemical data, pituitary tumors on MRI scans have to be interpreted carefully. Although it is tempting to regard them as diagnostic in patients with inappropriately high levels of TSH, pituitary incidentalomas can be found in up to $10 \%$ of the population (16). However, in the differential diagnosis of RTH, detection of a pituitary tumor is supportive for the diagnosis of TSH-oma. In our series, three patients had macro- and two microadenomas.
Taking clinical profile, biochemical tests and imaging findings into account, once diagnosis of TSH-oma is made, surgical adenomectomy of the pituitary adenoma should be pursued as first-line therapy. Only one of our patients underwent transsphenoidal adenomectomy. In all other cases, pituitary surgery was contraindicated or declined. Three patients received dopamine agonist therapy (cabergoline or bromocriptine). Bromocriptine was effective in lowering TSH levels in one patient. Another patient had to change from bromocriptine to cabergoline, which was better tolerated and resulted in a decrease of TSH (TSH under thyroid hormone supplementation: mean $3.2 \mathrm{mU} / \mathrm{l}$, range $2.6-$ $3.7 \mathrm{mU} / \mathrm{l}$; TSH under dopamine agonist therapy: mean $2.5 \mathrm{mU} / \mathrm{l}$, range 1.7-3.2 mU/l). Nevertheless, dopamine agonists do not usually cause shrinkage of the tumor (2). In the current literature, efficacy of dopamine agonist therapy is controversial (1, 2, 17-19), especially since the development of somatostatin analogs. However, although the number of patients reported in our study is limited and might not be representative, dopamine agonist therapy has proven to be effective in controlling TSH-omas in our small series. Nevertheless, administration of cabergoline in one patient led to a paradoxical increase of TSH and tachycardia within 
two days. After stopping cabergoline, TSH decreased to previous levels again. A similar case has been reported (20), but the mechanism remains unclear.

In a recent study (21), administration of octreotideLAR over two months showed significant reduction or normalization of free thyroid hormones in seven of eight patients with TSH-oma, while none of the patients with pituitary RTH responded to this therapy. In one patient of our series, therapy with a somatostatin analog resulted in shrinkage of the tumor as known to occur under octreotide in $50 \%$ of the patients (22). However, octreotide was not effective in lowering TSH levels in a long-term basis in our patient, although TSH-suppressive effects by octreotide are known to be present in more than $90 \%$ of TSH-omas (2). In our patient, stereotactic radiotherapy of the pituitary finally stabilized TSH levels and stopped growth of the adenoma.

Generally, in the therapy of TSH-oma, thyroid hormone levels should be kept at upper limits of normal to prevent an additional stimulus of the pituitary tumor to expand (11). It was suggested that feedback of free $\mathrm{T}_{3}$ and $\mathrm{T}_{4}$ on TSH might remain partially effective at lower levels of peripheral thyroid hormone in contrast to high levels as induced in the $\mathrm{T}_{3}$ suppression test.

It has to be taken into consideration that only surgical adenomectomy may lead to the 'cure' of TSHoma. Criteria of cure go beyond the establishment of euthyroidism and include the normalization of $\alpha$-SU, $\alpha$ SU/TSH ratio, peripheral markers of thyroid hormone action and dynamic tests, as well as pituitary imaging (23). However, when a surgical approach is contraindicated or declined, normalization of circulating thyroid hormone levels and stabilization or reduction of tumor size must be the primary goal. In any case, long-term follow-up including clinical, biochemical, and radiological monitoring is mandatory.

\section{Conclusion}

In conclusion, TSH-omas are a heterogeneous entity regarding their clinical presentation, hormonal profile and therapeutic response. For their diagnosis, laboratory findings, dynamic tests and imaging results have to be carefully considered simultaneously. Previous thyroid treatment can make differential diagnosis between TSHsecreting tumor and pituitary resistance to thyroid hormone extremely difficult. The primary goal in treatment of TSH-oma must be surgical adenomectomy. However, in some cases, this approach is not possible. Adequate medical therapy may result in stable disease and control of symptoms, especially if the clinical course of TSH-oma is benign and hardly aggressive. Although the number of patients presented in this series is rather small and may not be representative, our findings show the efficacy of dopamine agonist therapy especially in long-term management of benign TSH-oma.

\section{References}

1 Socin HV, Chanson P, Delemer B, Tabarin A, Rohmer V, Mockel J, Stevenaert A \& Beckers A. The changing spectrum of TSHsecreting pituitary adenomas: diagnosis and management in 43 patients. European Journal of Endocrinology 2003148 433-442.

2 Beck-Peccoz P, Brucker-Davis F, Persani L, Smallridge RC \& Weintraub BD. Thyrotropin-secreting pituitary tumors. Endocrine Reviews 199617 610-638.

3 Beck-Peccoz P, Roncoroni R, Mariotti S, Medri G, Marcocci C, Brabant G, Forloni F, Pinchera A \& Faglia G. Sex hormone-binding globulin measurement in patients with inappropriate secretion of thyrotropin (IST): evidence against selective pituitary thyroid hormone resistance in nonneoplastic IST. Journal of Clinical Endocrinology and Metabolism 199071 19-25.

4 Faglia G, Beck-Peccoz P, Piscitelli G \& Medri G. Inappropriate secretion of thyrotropin by the pituitary. Hormone Research 1987 26 79-99.

5 Weiss RE \& Refetoff S. Resistance to thyroid hormone. Reviews in Endocrine and Metabolic Disorders 20001 97-108.

6 Refetoff S, Weiss RE \& Usala SJ. The syndromes of resistance to thyroid hormone. Endocrine Reviews 199314 348-399.

7 Chatterjee VK \& Beck-Peccoz P. Hormone-nuclear receptor interactions in health and disease. Thyroid hormone resistance. Baillière's Clinical Endocrinology and Metabolism 1994 8 267-283.

8 Beck-Peccoz P \& Chatterjee VKK. The variable clinical phenotype in thyroid hormone resistance syndrome. Thyroid 1994 4 225-232.

9 Khandwala H \& Lee C. Inappropriate secretion of thyroidstimulating hormone. Canadian Medical Association Journal 2006 175 351-353.

10 Sanno N, Teramoto A \& Osamura RY. Thyrotropin-secreting pituitary adenomas. Clinical and biological heterogeneity and current treatment. Journal of Neuro-Oncology 200154 179-186.

11 Beck-Peccoz P \& Persani L. Variable biological activity of thyroidstimulating hormone. European Journal of Endocrinology 1994131 331-340.

12 Brucker-Davis F, Oldfield EH, Skarulis M, Doppman JL \& Weintraub BD. Thyrotropin-secreting pituitary tumors: diagnostic criteria, thyroid hormone sensitivity, and treatment outcome in 25 patients followed at the National Institutes of Health. Journal of Clinical Endocrinology and Metabolism 199984 476-486.

13 Kourides IA, Ridgway EC, Weintraub BD, Bigos ST, Gershengorn MC \& Maloof F. Thyrotropin-induced hyperthyroidism: use of alpha and beta subunit levels to identify patients with pituitary tumors. Journal of Clinical Endocrinology and Metabolism 197745 534-543.

14 Terzolo M, Orlandi F, Bassetti M, Medri G, Paccotti D, Cortelazzi D, Angeli A \& Beck-Peccoz P. Hyperthyroidism due to a pituitary adenoma composed of two different cell types, one secreting alphasubunit alone and another cosecreting alpha-subunit and thyrotropin. Journal of Clinical Endocrinology and Metabolism $199172415-421$.

15 Beckers A, Abs R, Mahler C, Vandalem JL, Pirens G, Hennen G \& Stevenaert A. Thyrotropin-secreting pituitary adenomas: report of seven cases. Journal of Clinical Endocrinology and Metabolism 1991 72 477-483.

16 Hall WA, Luciano MG, Doppman JL, Patronas NJ \& Oldfield EH. Pituitary magnetic resonance imaging in normal human volunteers: occult adenomas in the general population. Annals of Internal Medicine 1994120 817-820.

17 Shomali ME \& Katznelson L. Medical therapy for gonadotroph and thyrotroph tumors. Endocrinology and Metabolism Clinics of North America 199928 223-240.

18 Bevan JS, Burke CW, Esiri MM, Adams CB, Ballabio M, Nissim M \& Faglia G. Studies of two thyrotropin-secreting pituitary adenomas: evidence for dopamine receptor deficiency. Clinical Endocrinology 198931 59-70.

19 Beck-Peccoz P \& Persani L. Medical management of thyrotropinsecreting pituitary adenomas. Pituitary 20025 83-88. 
20 Chanson P, Orgiazzi J, Derome PJ, Bression D, Jedynak CP, Trouillas J, Legentil P, Racadot J \& Peillon F. Paradoxical response to thyrotropin to L-dopa and presence of dopaminergic receptors in a thyrotropin-secreting pituitary adenoma. Journal of Clinical Endocrinology and Metabolism $198459542-546$.

21 Mannavola D, Persani L, Vannucchi G, Zanardelli M, Fugazzola L, Verga U, Vacchetti M \& Beck-Peccoz P. Different responses to chronic somatostatin analogues in patients with central hyperthyroidism. Clinical Endocrinology 200562 176-181.

22 Chanson P, Weintraub BD \& Harris AG. Octreotide therapy for thyroid-stimulating hormone-secreting pituitary adenomas.
A follow-up of 52 patients. Annals of Internal Medicine 1993 $119236-240$.

23 Losa M, Giovanelli M, Persani L, Mortini P, Faglia G \& BeckPeccoz P. Criteria of cure and follow-up of central hyperthyroidism due to thyrotropin-secreting pituitary adenomas. Journal of Clinical Endocrinology and Metabolism 199681 3084-3090.

Received 14 February 2007

Accepted 19 April 2007 